\title{
Sphenochoanal Polyp
}

Saurabh Agarwal, Aseem Mishra, Mohan Jagade, VG Kasbekar, Vandana Thorawade, Shreyas Joshi

\section{ABSTRACT}

Nasal polyps are mostly referred to antrochoanal polyps and a sphenoid polyp is as such a rare entity. Computerized tomography and nasal endoscopy have contributed to an increase of accuracy in the diagnosis of these masses. Simple polypectomy that leaves some part of the polyp inside the sphenoid sinus carries a high risk of recurrence. Destructive external approaches to gain access to the sphenoid sinus are also not advisable in children for a benign disease. We present here a case of sphenochoanal polyp arising from right side sphenoid sinus. The sphenoid sinus disease is very rare and can be well-managed with endoscopic sinus surgery.

Keywords: S phenochoanal, Polyp, Endoscopic sinus surgery.

How to cite this article: Agarwal S, Mishra A, J agade $M$, Kasbekar VG, Thorawade V, J oshi S. Sphenochoanal Polyp. Clin Rhinol An Int J 2013;6(1):54-55.

\section{Source of support $\mathrm{Nil}$}

Conflict of interest: None declared

\section{INTRODUCTION}

There are three types of choanal polyps antrochoanal, sphenochoanal and ethmochoanal polyps. It has 3 parts intrasinusal portion, ostial and extrasinusal or choanal portion. The sphenochonal polyps are very uncommon. It is believed to be caused by prolapsed of the sinus mucosa or due to cyst placed in the sinus that grows gradually projecting itself through drainage ostium. The target of this study is to present the case of a patient with progressive nasal obstruction complaints at right side. Its diagnostic investigation showed a large sphenochoanal polyp, which was completely removed through nasal endoscopy approach.

\section{CASE REPORT}

A 19-year-old female presents with 9 months history of bilateral nasal obstruction and headache. On anterior rhinoscopy there is a poly poidal mass visible in the posterior part of right nasal cavity. Oral cavity examination shows mass hanging from the nasopharynx (Fig. 1). The computed tomographic (CT) scan of the PNS shows a mass arising in the right sphenoid sinus involving the nasopharynx and reaching the oral cavity (Fig. 2). Nasal endoscopy reveals mass in completely obliterating both the posterior choanal and the mass was extending through the sphenoethmoidal recess. Ophthalmological examination and cranial nerves examination was normal.

The polyp was removed endoscopically under general anesthesia (Fig. 3). Histopathology confirmed the diagnosis of inflammatory polyp. At 3 months follow-up patient was

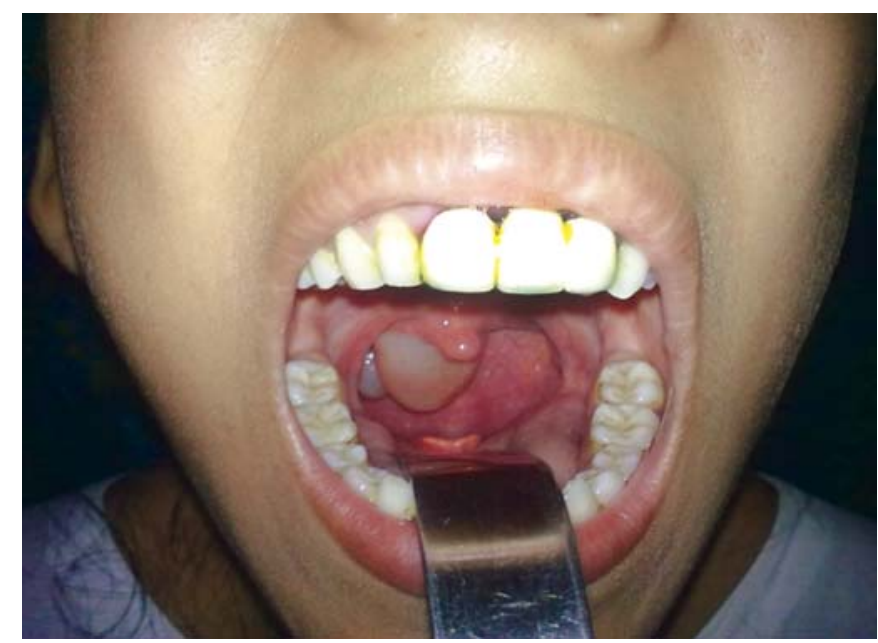

Fig. 1: Polyp seen in oral cavity

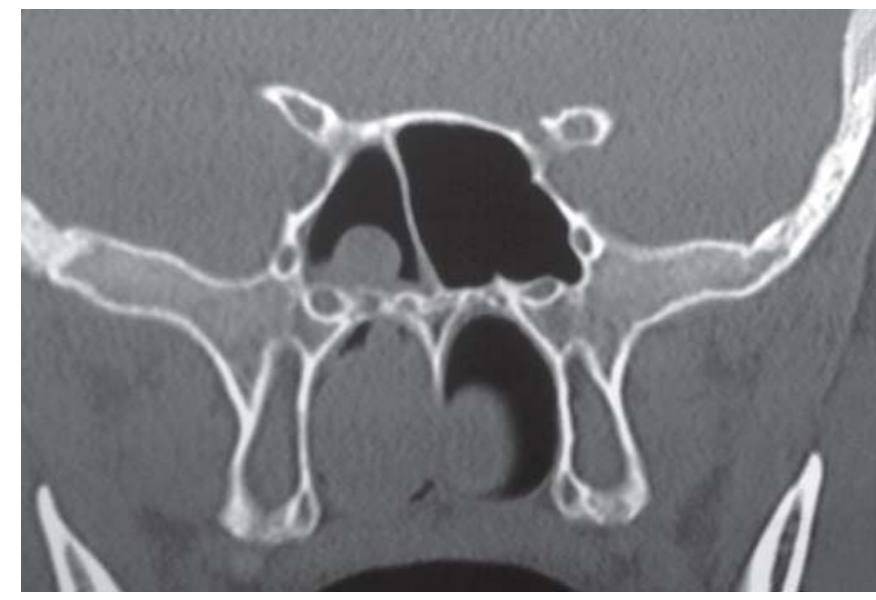

Fig. 2: CT scan showing sphenochoanal polyp

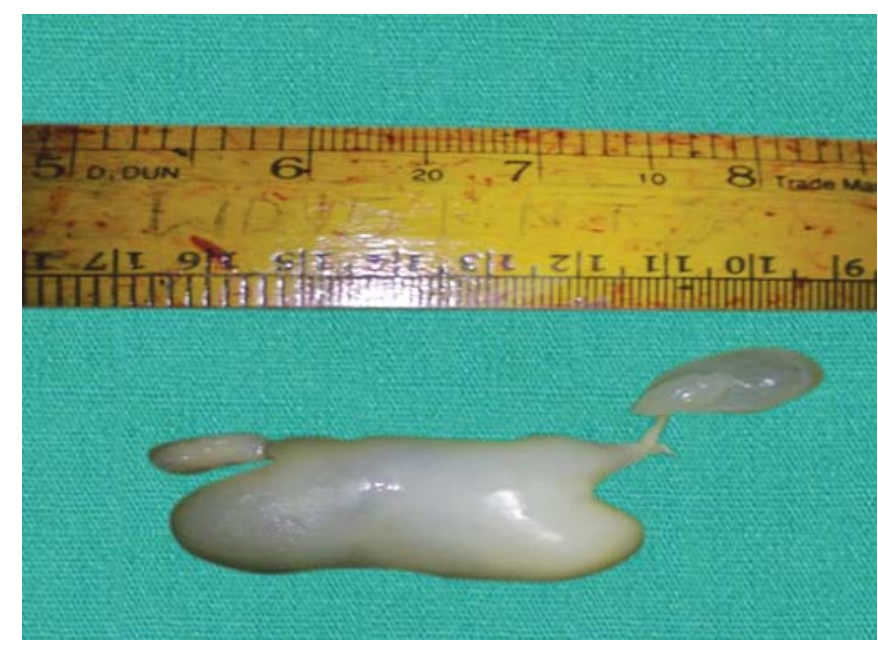

Fig. 3: Specimen of sphenochoanal polyp dissected out

asymptomatic and endoscopy did not reveal any mass in the nasal cavity. 


\section{DISCUSSION}

Sphenochoanal polyp cases go unreported due to inability to clinically examine the sinus and inadequate radiological examination. The CT PNS has lead to accurate diagnosis of the sphenoid polyps and masses and the important anatomical relationship of the sphenoid sinus remarks special attention owing to the complications arising due to untreated cases of mass in a sphenoid sinus. ${ }^{1}$

The sphenoid polyp usually presents before 40 years of age with major percentage in the adolescent and young adults. $^{2}$

Lim and Sdralis hypothesize that sphenochoanal polyps are inflammatory in origin and most are small and asymptomatic, though polyps enlarge over a few years because of persistent infection and may eventually become symptomatic. $^{3}$

The most common presenting complaint is headache. ${ }^{4}$ In certain studies the nasal obstruction is the commonest symptom. $^{2}$

Definitive diagnosis of a nasal polyp can be made by nasal endoscopy where the polyp can be seen coming through the sphenoethmoidal recess and going into the sphenoid sinus through the ostium. CT PNS will help in localizing the polyp and evaluating the extent and site of origin. Contiguous axial and coronal CT scan will help in differentiating an antrochoanal polyp from a sphenoidal polyp.

Sphenochoanal polyp being a rare entity and thus necessitates investigation prior to surgical treatment. Examination of cranial nerves and ophthalmological examination becomes necessary to rule out any compression symptoms owing to sphenoid sinus mass.

Sphenochoanal polyps can be managed by endoscopic sinus surgery ${ }^{5}$ and it is associated with lower recurrence rates as compared to polypectomy and it is associated with less postoperative pain, minimal blood loss, quick recovery and short hospital stay.

\section{CONCLUSION}

Sphenochoanal polyp is a rare cause of polyposis. It can be differentiated from other polyps through CT paranasal sinus.
It can be managed well with endoscopic sinus surgery with complete removal and lower recurrence.

\section{REFERENCES}

1. Sethi DS. Isolated sphenoid lesions: Diagnosis and management. Otolaryngol Head Neck Surg 1999 M ay;120(5):730-36.

2. Vuysere S, Hermans R, M archal G. Sinochoanal polyp and its variant, the angiomatous polyp: MRI findings. Eur Radiol 2001;11(1):55-58.

3. Lim WK, Sdralis T. Regression of a sphenochoanal polyp in a child. Laryngoscope 2004 M ay;114(5):903-05.

4. Nayak DR, Pujary K, V aliathan M, Parul P, Kamat A. Sphenochoanal polyp with heterotopic glial tissue. J Laryngol Otol $2007 \mathrm{M}$ ar; 121(3):274-76.

5. Bist SS, B isht M , K umar R, V arshney S. Sphenochoanal polyp: A $n$ endoscopic view. Ear Nose Throat] 2007 J an;86(1):19-20.

\section{ABOUT THE AUTHORS}

\section{Saurabh Agarwal}

Chief R esident, D epartment of ENT, G rant M edical College, M umbai M aharashtra, India

Correspondence Address: Room N o. 712, 300 Resident Doctors Hostel, JJ Hospital, Byculla, M umbai-400008, M aharashtra, India Phone: +91-9967944504, e-mail: dr.saurabhagarwal@ yahoo.com

\section{Aseem Mishra}

Resident, Department of ENT, Grant Medical College, M umbai $M$ aharashtra, India

\section{Mohan Jagade}

Professor and Head, Department of ENT, Grant Medical College M umbai, M aharashtra, India

\section{VG Kasbekar}

Professor and Head, Department of ENT, Grant Medical College M umbai, M aharashtra, India

\section{Vandana Thorawade}

Lecturer, Department of ENT, Grant Medical College, M umbai M aharashtra, India

\section{Shreyas Joshi}

J unior R esident, Department of ENT, Grant M edical College, M umbai M aharashtra, India 